\title{
Biodiversity of Lactococcus lactis bacteriophages in Polish dairy environment ${ }^{\not{H}}$

\author{
Agnieszka K. Szczepańska ${ }^{{ }^{\star}}$, Monika S. Hejnowicz ${ }^{1^{\star}}$, Piotr Kołakowski ${ }^{2}$ \\ and Jacek Bardowski ${ }^{1}$ \\ ${ }^{1}$ Department of Microbial Biochemistry, Institute of Biochemistry and Biophysics, Polish Academy of Sciences, \\ Warszawa, Poland; ${ }^{2}$ Danisco Biolacta, Innovation, Olsztyn, Poland
}

Received: 25 September, 2006; revised: 15 January, 2007; accepted: 07 February, 2007 available on-line: 09 March, 2007

\begin{abstract}
We present here the results of an exploration of the bacteriophage content of dairy wheys collected from milk plants localized in various regions of Poland. Thirty-three whey samples from 17 regions were analyzed and found to contain phages active against L. lactis strains. High phage titer in all whey samples suggested phage-induced lysis to be the main cause of fermentation failures. In total, over 220 isolated phages were examined for their restriction patterns, genome sizes, genetic groups of DNA homology, and host ranges. Based on DNA digestions the identified phages were classified into 34 distinct DNA restriction groups. Phage genome sizes were estimated at 14-35 kb. Multiplex PCR analysis established that the studied phages belong to two out of the three main lactococcal phage types - c2 and 936, while P335-type phages were not detected. Yet, analyses of bacterial starter strains revealed that the majority of them are lysogenic and carry prophages of P335-type in their chromosome. Phage geographical distribution and host range are additionally discussed.
\end{abstract}

Keywords: bacteriophages, Lactococcus lactis, biodiversity, dairy environment

\section{INTRODUCTION}

Bacteriophage attack is regarded as a serious problem in the dairy industry worldwide. Over the years, this circumstance has initiated extensive studies on bacteriophages occurring in dairies in Europe and other continents (Jarvis, 1977; Lembke et al., 1980; Relano et al., 1987; Powell et al., 1989; Prevots et al., 1990; Moineau et al., 1992; 1996; Casey et al., 1993; Miklic \& Rogelj, 2003; Sanlibaba \& Akcelik, 2005). Regardless of sanitary precautions, starter strain rotation or constant development of new phage-resistant bacterial strains, bacteriophage infections persist in the dairy industry (Sing \& Klaenhammer, 1993; Moineau et al., 1996). Raw milk, not fully aseptic conditions during the fermenta- tion process, prophage induction in lysogenic starter strains as well as the environment itself - air, appliances, whey, workers, etc. are commonly regarded as potential sources of bacteriophages (McIntyre et al., 1991). Once having emerged, phages can spread swiftly throughout the dairy plant. Their presence is difficult to eliminate due to their short latent period, relatively large burst size and/or resistance to pasteurization (Daly et al., 1996; Madera et al., 2004). Phage-induced bacterial cell lysis leads to failed or slow fermentation, decrease in acid production, reduction of milk products quality, e.g. taste and texture (Lawrence, 1978; Coffey \& Ross, 2002), which all result in profound economical losses.

Lactococcus lactis strains are widely used as starter cultures for milk fermentation during man-

\footnotetext{
$\star$ Equal contributors.

Presented at the 29th Meeting of the Federation of the European Biochemical Societies, Warsaw, Poland, 26 June-1 July 2004, Eur J Biochem 271 (Suppl 1:) 232, P6.2-32.

${ }^{\square}$ Corresponding author: Agnieszka K. Szczepańska, Department of Microbial Biochemistry, Institute of Biochemistry and Biophysics, Polish Academy of Sciences, A. Pawińskiego 5a, 02-106 Warszawa, Poland; tel.: (48 22) 592 1223; fax: (48 22) 658 4636; e-mail: agaszczep@ibb.waw.pl

Abbreviations: pfu, plaque forming units; rcf, relative centrifugation force.
} 
ufacturing of many types of cheeses, sour cream, buttermilk and kefir (Moineau et al., 1996). It is estimated that $60-70 \%$ of technological disruptions in production of cottage and hard cheeses is caused by bacteriophage infections of lactococcal strains (refer to Hejnowicz \& Bardowski, 2005). Due to its frequent application, many studies have concentrated on bacteriophages active against L. lactis. Lactococcal phages most frequently encountered in milk plants belong to one of three types: 936, c2 or P335 (Casey et al., 1993; Moineau et al., 1996; Schouler, 1996). Phages from the P335 type comprise of both temperate and lytic representatives, while c2- and 936-type phages execute only the lytic life cycle (Jarvis et al., 1991).

Phage infections of mesophilic starter cultures in the dairy environment in Poland evoke serious biotechnological problems. Despite this fact, no data is available on the ecology nor molecular characteristics of bacteriophages virulent for Lactococcus in our country.

Therefore, the objective of our work was to investigate Polish dairy whey samples in the context of bacteriophage content. It is also the first study of such kind on lactococcal bacteriophages in Poland. Knowledge of the types of phages encountered in milk fermentation environment was expected to supply data on phage biology and biodiversity that could serve for quick phage identification and allow selecting phage-resistant starter strains to overcome phage infections.

\section{MATERIALS AND METHODS}

Bacterial strains, bacteriophages and growth conditions. Bacterial strains and bacteriophages used in this study are listed in Table 1. Bacterial strains were cultured at $30^{\circ} \mathrm{C}$ in M17 broth (Terzaghi \& Sandine, 1975) containing $0.5 \%$ glucose (GM17) without shaking or on GM17 plates with $1.5 \%$ agar. A final concentration of $10 \mathrm{mM}$ of $\mathrm{CaCl}_{2}$ was added to the medium when phage lysates were prepared.

Bacteriophage propagation and purification. Techniques for phage titration and propagation were essentially as described previously (Sambrook et al., 1989) apart from specific modifications as to the medium and incubation temperatures appropriate for L. lactis.

Initially, whey samples were analyzed for the presence of phages by separately mixing serial dilutions of the samples with each of the industrial L. lactis strains and plating them on double-layer GM17 plates supplemented with $10 \mathrm{mM} \mathrm{CaCl}_{2}$. Phage detection and titer determination were followed by purification of chosen single plaques which was done by reductive streaking using small strips of sterile paper wetted in single phage plaque suspensions on a double-layer lawn of phage-sensitive bacteria.

Small and large scale bacteriophage propagation. Phage propagation was done by small or large scale lysis in liquid medium. Small scale lysis was performed by infecting $1 \mathrm{ml}$ of bacterial culture grown to an $\mathrm{OD}_{600} 0.2$ with purified single plaque picked from the plate by a sterile toothpick. Lysis on a large scale was performed in $200 \mathrm{ml}$ of culture grown to an $\mathrm{OD}_{600} 0.2$ infected with $0.2 \mathrm{ml}$ of the small volume lysate, containing phages at a concentration of approx. $10^{8} \mathrm{pfu} / \mathrm{ml}$. A volume of $2 \mathrm{ml}$ from large scale phage lysate was stored at $4^{\circ} \mathrm{C}$ as a high titer stock.

Isolation of phage DNA. Phage lysates obtained on a large scale were filtered using $0.45 \mu \mathrm{m}$ filters (Stericup Millipore). RNase and DNase (Sigma) were added to a final concentration of $20 \mu \mathrm{g} / \mathrm{ml}$ each and lysate incubated at $37^{\circ} \mathrm{C}$ for $1 \mathrm{~h}$. Subsequently, $\mathrm{NaCl}$ to a final concentration of $1 \mathrm{M}$ and $10 \%(\mathrm{w} / \mathrm{v})$ of polyethylene glycol $\left(\mathrm{PEG}_{6000}\right)$ in powder were added to the lysates and after being completely dissolved by vigorous shaking, stored overnight at $4^{\circ} \mathrm{C}$. Phage particle precipitates were recovered by centrifugation at $9000 \mathrm{rcf}$ for $20 \mathrm{~min}$ at $4^{\circ} \mathrm{C}$ and, after discarding the supernatant, suspended in TM buffer $(10 \mathrm{mM}$ Tris/ $\mathrm{HCl}, \mathrm{pH} 8,10 \mathrm{mM} \mathrm{MgCl} 2$ ). PEG and cell debris were extracted from phage suspensions by adding chloroform $(1: 1, \mathrm{v} / \mathrm{v})$ and vigorous vortexing (approx. 30 s). The water phase containing phage particles was recovered after $15 \mathrm{~min}$ of centrifugation at 21000 rcf. This was followed by extractions: once with phenol $(1: 1, \mathrm{v} / \mathrm{v})$ and lithium chloride $(1: 10, \mathrm{v} / \mathrm{v})$, twice with phenol $(1: 1, \mathrm{v} / \mathrm{v})$ and once with phenol/chloroform solution $(1: 1, v / v)$. Finally, DNA was precipitated from the water phase with cold $96 \%$ ethanol $(1: 2$, $\mathrm{v} / \mathrm{v})$. DNA was recovered by centrifugation at 21000 rcf for $30 \mathrm{~min}$ at $4^{\circ} \mathrm{C}$, and washed with $70 \%$ ethanol. After drying, the precipitates were dissolved in 100 $\mu \mathrm{TE}$ buffer (10 mM Tris/HCl, $1 \mathrm{mM}$ EDTA, $\mathrm{pH}$ 8) and stored at $-20^{\circ} \mathrm{C}$.

DNA manipulation and gel electrophoresis. DNA manipulations were performed by standard techniques (Sambrook et al., 1989). Purified phage DNA was digested with EcoRI, EcoRV, HindIII and HincII restriction endonucleases supplied by Boehringer-Mannheim and used as recommended by the manufacturer. Digested DNA samples were analyzed on $0.8 \%$ agarose gel containing $0.25 \mu \mathrm{g} / \mathrm{ml}$ ethidium bromide in $1 \times \mathrm{TAE}$ buffer $(0.04 \mathrm{M}$ Tris, $0.04 \mathrm{M}$ acetic acid, $1 \mathrm{mM}$ EDTA, final $\mathrm{pH}$ 8.0). Markers-GeneRuler ${ }^{\mathrm{TM}} 1 \mathrm{~kb}$ DNA Ladder (Fermentas) and GeneRuler ${ }^{\mathrm{TM}}$ DNA Ladder Mix (Fermentas) were used as relative molecular weight references.

Total DNA isolation from bacterial cells. Total DNA was isolated from L. lactis cells by the fol- 
Table 1. Bacterial strains and bacteriophages

\begin{tabular}{|c|c|c|c|}
\hline \multicolumn{2}{|c|}{ Bacterial strain or phage } & Relevant properties & Reference \\
\hline \multicolumn{4}{|c|}{ L. lactis strains } \\
\hline \multicolumn{2}{|c|}{$\begin{array}{l}\text { Industrial starter strains of L. lactis ssp. lactis } \\
\text { L. lactis ssp. lactis var. diacetylactis, L. lactis ssp. cremoris }\end{array}$} & unknown & Rhodia Food Biolacta \\
\hline \multicolumn{2}{|c|}{ L. lactis ssp. lactis IL1403 } & plasmid-free & Chopin, 1984 \\
\hline \multicolumn{2}{|c|}{ L. lactis ssp. cremoris MG1363 } & plasmid-free & Gasson, 1983 \\
\hline \multicolumn{4}{|c|}{ Bacteriophages } \\
\hline c2 & \multicolumn{2}{|l|}{ c2-type representative phage } & Pillidge \& Jarvis, 1988 \\
\hline 712 & \multicolumn{2}{|l|}{ 936-type representative phage } & Gasson, 1983 \\
\hline P335 & \multicolumn{2}{|l|}{ P335-type representative phage } & Braun et al., 1989 \\
\hline bIBBg6/5 & \multicolumn{2}{|l|}{ c2-type } & this study \\
\hline bIBB588 $\mathrm{p}_{1}$ & \multicolumn{2}{|l|}{ c2-type } & this study \\
\hline bIBB9 $4 \mathrm{p}_{4}$ & \multicolumn{2}{|l|}{ c2-type } & this study \\
\hline bIBB94g & \multicolumn{2}{|l|}{ c2-type } & this study \\
\hline bIBB24g 2 & \multicolumn{2}{|l|}{ c2-type } & this study \\
\hline $\mathrm{bIBB}_{24 \mathrm{tp}_{1}}$ & \multicolumn{2}{|l|}{ 936-type } & this study \\
\hline bIBB5g $_{1}$ & \multicolumn{2}{|l|}{ 936-type } & this study \\
\hline $\mathrm{bIBBEg}_{1}$ & \multicolumn{2}{|l|}{ 936-type } & this study \\
\hline bIBB2a & \multicolumn{2}{|l|}{ 936-type } & this study \\
\hline bIBB3a & \multicolumn{2}{|l|}{ 936-type } & this study \\
\hline bIBB5a & \multicolumn{2}{|l|}{ 936-type } & this study \\
\hline bIBB8a & \multicolumn{2}{|l|}{ 936-type } & this study \\
\hline bIBB10a & \multicolumn{2}{|l|}{ 936-type } & this study \\
\hline bIBB40a & \multicolumn{2}{|l|}{ 936-type } & this study \\
\hline bIBB1 & \multicolumn{2}{|l|}{ 936-type } & this study \\
\hline bIBB5 & \multicolumn{2}{|l|}{ 936-type } & this study \\
\hline bIBB8 & \multicolumn{2}{|l|}{ 936-type } & this study \\
\hline bIBB12 & c2-type & & this study \\
\hline bIBB14 & c2-type & & this study \\
\hline bIBB18 & c2-type & & this study \\
\hline bIBB19 & c2-type & & this study \\
\hline bIBB20 & c2-type & & this study \\
\hline bIBB22 & c2-type & & this study \\
\hline bIBB27 & c2-type & & this study \\
\hline bIBB27a & c2-type & & this study \\
\hline bIBB29 & 936-type & & this study \\
\hline bIBB36 & c2-type & & this study \\
\hline bIBB47 & 936-type & & this study \\
\hline bIBB50 & 936-type & & this study \\
\hline bIBB55 & c2-type & & this study \\
\hline bIBB61 & c2-type & & this study \\
\hline bIBB77 & c2-type & & this study \\
\hline bIBB89 & c2-type & & this study \\
\hline bIBB95 & c2-type & & this study \\
\hline
\end{tabular}

lowing method: cells from $2 \mathrm{ml}$ of overnight cultures were harvested, washed and suspended in $0.2 \mathrm{ml}$ of TES-lysozyme solution $(25 \mathrm{mM}$ Tris/ $\mathrm{HCl}, 0.1 \mathrm{M}$ EDTA, 25\% (w/v) saccharose $\mathrm{pH} 8$, lysozyme $8 \mathrm{mg} /$ $\mathrm{ml}$ ). After $15 \mathrm{~min}$ of incubation at $37^{\circ} \mathrm{C}, 15 \mu \mathrm{l}$ of $20 \%$ SDS solution was added and samples were incubated for $5 \mathrm{~min}$ at $75^{\circ} \mathrm{C}$. Cell lysates were extracted with $0.5 \mathrm{ml}$ of $1: 1 \mathrm{phenol} / \mathrm{chloroform}$ solution $(1: 1$, $\mathrm{v} / \mathrm{v})$. After centrifugation (15 $\mathrm{min}, 21000 \mathrm{rcf})$ the water phase was recovered. The phenol/chloroform extraction was repeated twice. Finally, total DNA was precipitated with $3 \mathrm{M}$ sodium acetate $(1: 10, \mathrm{v} /$ $\mathrm{v}, \mathrm{pH} 4.8)$ and ice cold $96 \%$ ethanol $(1: 2, \mathrm{v} / \mathrm{v})$. Af- ter centrifugation (15 $\mathrm{min}, 21000 \mathrm{rcf}$ ), the pellet was washed with $70 \%$ ethanol, dried and dissolved in 50 $\mu \mathrm{l}$ of demineralized water with RNase $(100 \mu \mathrm{g} / \mathrm{ml})$.

Multiplex PCR. Classification of phages into specific genetic types was performed by multiplex PCR using primers and conditions described elsewhere (Labrie \& Moineau, 2000) with $1 \mu$ of either: original whey samples, purified phage lysates or chromosomal DNA of industrial strains as a template. Phages c2, 712 (936-type) and P335 were used as reference phages of the three main genetic types.

Host range assays. To determine the host range of phages, growth of infected lactococcal strain 

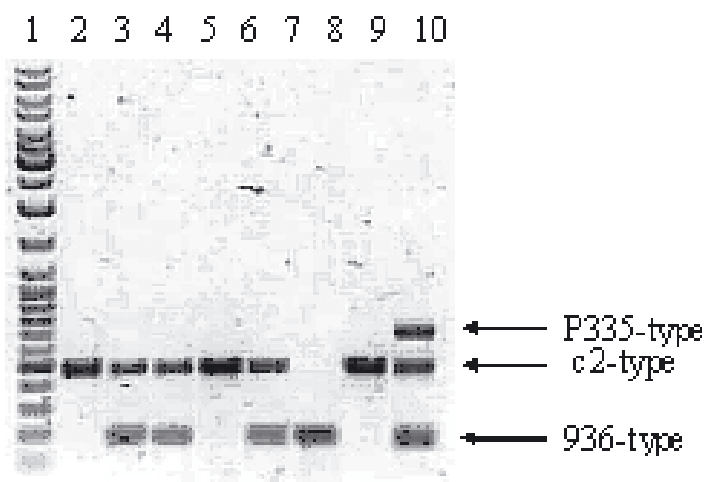

Figure 1. Detection of L. lactis phages in whey samples by multiplex PCR.

Primers specific for 936, c2 and P335 phages were used. Lane 1, GeneRuler ${ }^{\mathrm{TM}}$ DNA Ladder Mix (Fermentas); lanes 2-9, whey samples $(1 \mu \mathrm{l})$; lane 10, PCR products obtained from 936-, c2- and P335-type reference phages.

cultures was assayed at $30^{\circ} \mathrm{C}$ in a Microbiology Reader Analyzer (Bioscreen C; ThermoLabsystems). In the experiment, $4 \mu \mathrm{l}$ of diluted high titer phage stock $\left(10^{8} \mathrm{pfu} / \mathrm{ml}\right)$ was added to $200 \mu \mathrm{l}$ of bacterial cultures at $\mathrm{OD}_{600} 0.2$, after which the cultures were monitored for at least $12 \mathrm{~h}$ and $\mathrm{OD}_{600}$ measurements taken every $15 \mathrm{~min}$.

\section{RESULTS}

Verification of the presence of bacteriophages in industrial whey samples

Thirty-three whey samples from milk factories located in various regions of Poland were examined for the presence of L. lactis phages. Initial screening by multiplex PCR served for a rapid detection of lactococcal phages that belong to the three prevailing lactococcal phage types - c2, 936 and P335. Results of the assay established that phages are unambiguously present in all analyzed wheys (Fig. 1). Among them, 27\% wheys contained both c2- and 936-type phages, 30\% - only c2-type phages, whereas in $43 \%$ of whey samples only 936-type phages were found. Overall, 936-type phages were detected in 23 (69\%) of whey samples, which implied that they appear more frequently than c2-type phages.

Individual phages were isolated and purified against $15 \mathrm{~L}$. lactis strains selected from a collection of industrial starters. Those strains which exhibited the highest sensitivity towards phage development were used for further phage propagations. In parallel, phage titer in wheys was determined to vary in the range of $10^{3}-10^{12} \mathrm{pfu} / \mathrm{ml}$, but in the majority of cases it was around $10^{9} \mathrm{pfu} / \mathrm{ml}$. High titer suggested that phage-induced lysis was the most plausible factor for the failure of fermentation processes from which the

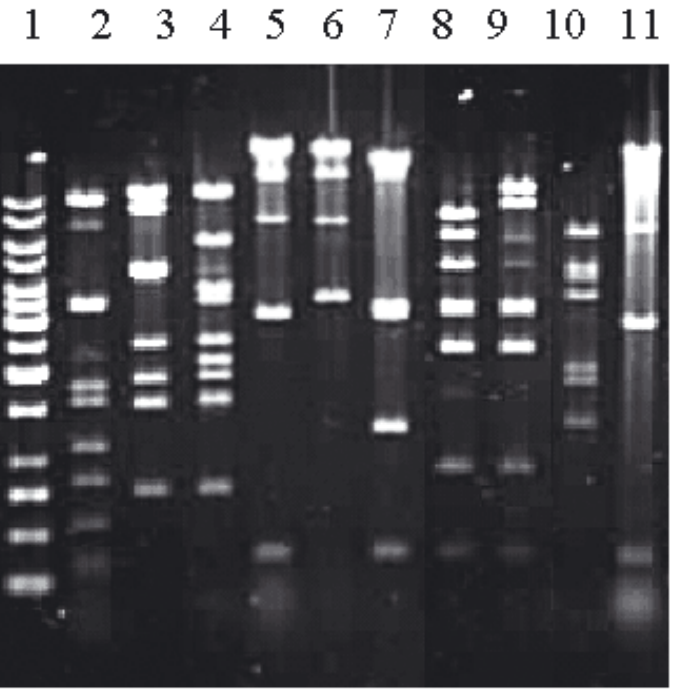

Figure 2. EcoRI-restriction DNA patterns of chosen representative phage isolates.

Lane 1, GeneRuler ${ }^{\mathrm{TM}} 1 \mathrm{~kb}$ DNA Ladder (Fermentas); lane 2, bIBB36; lane 3, bIBB47; lane 4, bIBB50; lane 5, bIBB55;

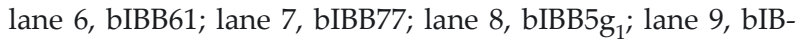
$\mathrm{BEg}_{1}$; lane 10, bIBB89; lane 11, bIBB95.

whey samples had been taken. Based on the morphological features of phage plaques (shape and size) a representative number of plaques (between 5 and 20) from each whey were taken for further examination. As a result, over 200 phage plaques were isolated and purified. Finally, high titer $\left(10^{9}-10^{11} \mathrm{pfu} / \mathrm{ml}\right)$ phage stocks were prepared by propagating the purified phage plaques in liquid medium. Overall, 223 phage isolates were obtained and subjected to physiological and molecular studies.

\section{Determination of phage DNA restriction patterns}

All isolated phages were examined for their restriction patterns with EcoRI, EcoRV, HindIII and HincII. EcoRI was determined to be the best in discriminating among the phage DNA samples and was chosen for further digestions (Fig. 2). In effect, 223 phage isolates were grouped into 34 distinct phage restriction groups. Moreover, total phage genome

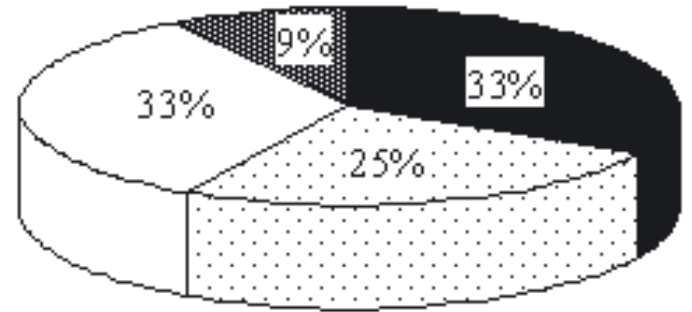

Figure 3. Number of phage DNA restriction groups found in analyzed wheys.

Percentage of wheys containing phages from: one (9), two (25), three (33) or four (33, black) restriction groups. 


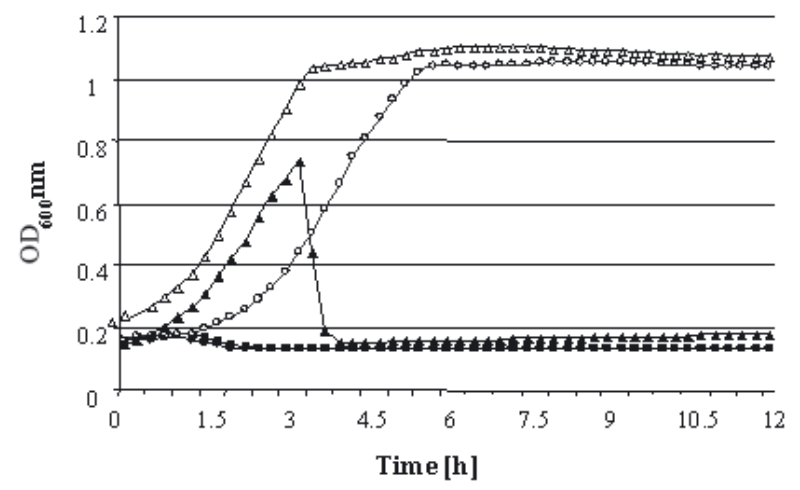

Figure 4. Lytic development of representative bacteriophages on selected L. lactis starter strain cultures.

Uninfected L. lactis IBB1793B (O), IBB1793B infected with bIBB5g $_{1}(\bullet)$, IBB1793B infected with $\operatorname{bIBBEg}_{1}(\boldsymbol{\square})$, uninfected IBB1784B $(\Delta)$, IBB1784B infected with bIBB29 $(\boldsymbol{\Delta})$. Strains were grown on GM17 at $30^{\circ} \mathrm{C}$ until $\mathrm{OD}_{600} 0.2$ after which the cultures were infected at high multiplicity of infection.

sizes were assessed by summing up the molecular sizes of EcoRI restriction fragments and determined to range from 14 to $35 \mathrm{~kb}$.

In the majority of wheys phages exhibiting different restriction patterns were detected; $67 \%$ of the samples contained phages representing two or more restriction groups (Fig. 3). Among the 34 distinct restriction groups determined, two, represented by phages bIBB5g $g_{1}$ and bIBBEg$_{1}$, were the most prevalent. They were detected, respectively, in 5 and 10 out of the 33 wheys analyzed.

Phage classification into genetic groups of homology

To classify the isolated phages into distinct genetic groups, multiplex PCR analysis was performed using primers specific for detecting DNA homology to c2-, 936- or P335-type phages. Among the phages with distinct restriction patterns determined an equal distribution of c2- (17) and 936-type (17) phages was shown, in contrast to P335-type phages which were not detected at all. The most prevalent bacteriophages - bIBB5g $g_{1}$ and bIBBEg $_{1}$ - were classed as 936 type. To further investigate the lack of P335-type phages in the whey samples, multiplex PCR was performed using type-specific primers on total DNA extracts from industrial starter strains. Notably, in $75 \%$ of the strains tested a product specific for P335-type phages was detected (not shown). Such a result suggested presence prophages of P335-type in chromosomes of the majority of the starter strains.

Dynamics of infection and phage host range assays

To determine the host range and dynamics of infection representative phages from each restric-

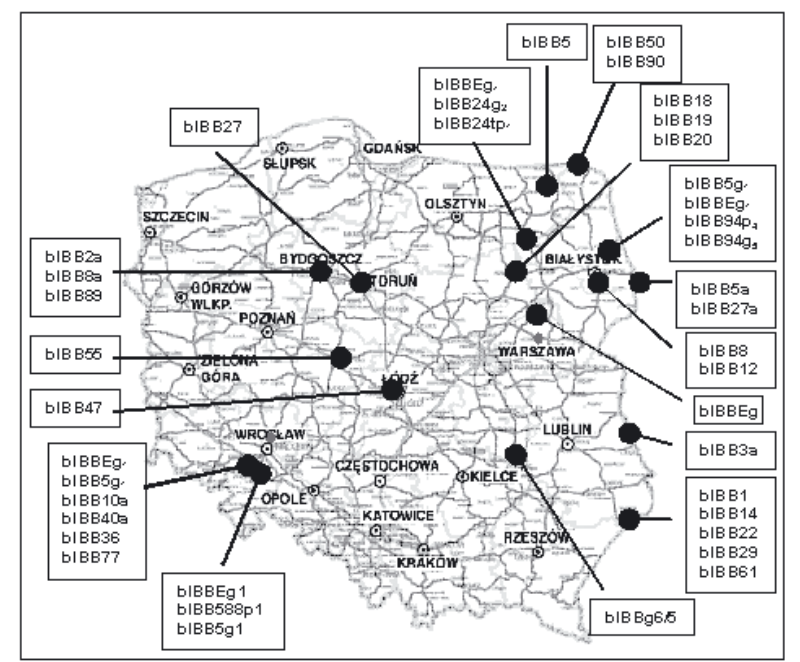

Figure 5. Geographical distribution of virulent lactococcal phages in dairy environment in Poland.

Map shows the regional origin of phage isolates.

tion group were tested against 15 different L. lactis ssp. lactis, L. lactis ssp. lactis var. diacetylactis, L. lactis ssp. cremoris industrial starter strain cultures. Four strains, namely IBB1783B, IBB1788B, IBB1794B and IBB1800B, were resistant to all of the examined phages (Table 2). Otherwise, lysis of nearly all phage-sensitive bacterial cultures occurred approximately $2 \mathrm{~h}$ after infection which implied a rather fast phage infection rate (Fig. 4). Among them, four strains appeared highly susceptible to phage infections and were lysed by representative phages from the c2- as well as the 936-type. Most of the phages, representative of all restriction groups, demonstrated a narrow host range. Phages representatives of 23 out of 34 restriction groups were active against only one strain; phage representatives from 9 other restriction groups were active against two strains, while only two phage representatives from the remaining groups lysed three strains. Phages belonging to the c2-type displayed a wider host range than 936-type phages. Notably, $41 \%$ of c2-type phages studied infected more than two strains, while the majority of the identified 936-type phages were lytic for only one strain. Two 936-type phages most commonly detected - bIBB5g $_{1}$ and bIBBEg $_{1}$ - were active on only one strain.

\section{Analysis of the geographical distribution of the isolated dairy bacteriophages}

The biodiversity of wheys supplied from 17 different regions in Poland was studied in respect to the region of origin by examining their phage content (Fig. 5). In all wheys at least one original phage was present. Phages prevalent in several regions were also identified - the most frequently appear- 
Table 2. L. lactis strain sensitivity towards isolated phages

\begin{tabular}{|c|c|c|c|c|c|c|c|c|c|c|c|c|c|c|c|c|}
\hline \multirow[t]{2}{*}{ Phage } & \multirow{2}{*}{\begin{tabular}{|l|} 
Phage \\
type
\end{tabular}} & \multicolumn{15}{|c|}{\begin{tabular}{|l|} 
Bacterial strain \\
\end{tabular}} \\
\hline & & $\begin{array}{l}\text { IBB } \\
094\end{array}$ & \begin{tabular}{|l|} 
IBB \\
1767B
\end{tabular} & \begin{tabular}{|l|} 
IBB \\
$1772 B$
\end{tabular} & $\begin{array}{l}\text { IBB } \\
1780 B\end{array}$ & \begin{tabular}{|l|} 
IBB \\
$1782 B$
\end{tabular} & \begin{tabular}{|l|} 
IBB \\
$1783 B$
\end{tabular} & \begin{tabular}{|l|} 
IBB \\
$1784 B$
\end{tabular} & \begin{tabular}{|l|} 
IBB \\
$1787 B$
\end{tabular} & $\begin{array}{l}\text { IBB } \\
1788 B\end{array}$ & \begin{tabular}{|l|} 
IBB \\
$1791 B$
\end{tabular} & $\begin{array}{l}\text { IBB } \\
\text { 1793B }\end{array}$ & \begin{tabular}{|l|} 
IBB \\
$1794 B$
\end{tabular} & \begin{tabular}{|l|} 
IBB \\
$1796 B$
\end{tabular} & $\begin{array}{l}\text { IBB } \\
1800 B\end{array}$ & \begin{tabular}{|l|} 
IBB \\
$1807 \mathrm{~B}$
\end{tabular} \\
\hline bIBBg6/5 & c2 & & & & & & & & & & & & & & & + \\
\hline bIBB588 $p_{1}$ & c2 & & & & & & & & & & & & & + & & \\
\hline bIBB94p $_{4}$ & $\mathrm{c} 2$ & + & & & & & & & & & & & & & & \\
\hline bIBB94g $g_{5}$ & $\mathrm{c} 2$ & + & & & & & & & & & & & & & & \\
\hline bIBB24g ${ }_{2}$ & c2 & & & & & & & & & & & + & & & & \\
\hline bIBB24tp ${ }_{1}$ & 936 & & & & & & & & & & & + & & & & \\
\hline bIBB5g $_{1}$ & 936 & & & & & & & & & & & + & & & & \\
\hline bIBBEg $_{1}$ & 936 & & & & & & & & & & & + & & & & \\
\hline bIBB2a & 936 & & & & & & & & + & & & & & & & \\
\hline bIBB 3a & 936 & & & & & & & & + & & & & & & & \\
\hline bIBB 5a & 936 & & & & & & & & + & & & & & & & \\
\hline bIBB 8a & 936 & & & & & & & & & & & + & & & & \\
\hline bIBB 10a & 936 & & & & & & & & & & & + & & & & \\
\hline bIBB 40a & 936 & & & & & & & & & & & + & & & & \\
\hline bIBB 1 & 936 & & & & + & & & & & & + & & & & & \\
\hline bIBB 5 & 936 & & & & + & & & & & & + & & & & & \\
\hline bIBB 8 & 936 & & & & + & & & & & & + & & & & & \\
\hline bIBB 12 & $\mathrm{c} 2$ & & & & & & & & + & & & & & & & \\
\hline bIBB 14 & c2 & & & & & & & + & & & & & & + & & \\
\hline bIBB 18 & c2 & & & & & & & + & & & & & & + & & \\
\hline bIBB 19 & c2 & & & & & & & + & & & & & & + & & \\
\hline bIBB 20 & c2 & & & & & & & + & & & & & & + & & \\
\hline bIBB 22 & c2 & & & & & & & + & & & & & & + & & \\
\hline bIBB 27 & c2 & & & & + & & & + & & & & & & + & & \\
\hline bIBB 27a & c2 & & & & & & & & & & & & & + & & \\
\hline bIBB 29 & 936 & & & & & & & + & & & & + & & + & & \\
\hline bIBB 36 & c2 & & & + & & & & & & & & & & & & \\
\hline bIBB 47 & 936 & & & & + & & & & & & & & & & & \\
\hline bIBB 50 & 936 & & & & + & & & & & & & & & & & \\
\hline bIBB 55 & c2 & & & & & & & & & & & & & & & + \\
\hline bIBB 61 & $\mathrm{c} 2$ & & & & & + & & & & & & & & & & + \\
\hline bIBB 77 & $\mathrm{c} 2$ & & & & & + & & & & & & & & & & \\
\hline bIBB 89 & $\mathrm{c} 2$ & & + & & & & & & & & & & & & & \\
\hline bIBB 95 & c2 & & & & & & & & & & & & & + & & \\
\hline
\end{tabular}

ing phages - bIBB5g $_{1}$ and bIBBEg $_{1}$ - were found respectively in three and seven out of 17 analyzed areas. Yet, our observations show that the majority of phages seem to be specific to geographical regions. Most probably this is directly due to the starter strains used in the dairy plants.

\section{DISCUSSION}

This work provides novel data on lactococcal bacteriophages in Poland. Phage infections of the mesophilic lactococcal starters constitute a serious biotechnological problem in Polish dairy plants. Yet, no details about their molecular features or ecology are available. Our 2-year study resulted in estab- lishing a wide collection of lactococcal lytic bacteriophages isolated from the dairy environment. Basic molecular genetic techniques allowed determining such characteristics as restriction patterns, genome sizes, genetic similarities and host ranges. We determined that all wheys contained phages at a high titer which implied that phage infections were the most certain cause of fermentation perturbations.

The range of phages detected in the analyzed whey samples reflects the great diversity of phages that persist in dairy plants. A comparison of DNA restriction patterns revealed a number of similarities among the studied phages that suggest either partial conservation of phage genetic content or events of extensive DNA recombination that occur between them. Genetic type classification assays grouped the phages detected 
in wheys into either c2 or 936 types, which comprise phages that execute only the lytic cycle. This excluded the possibility that the isolated phages could originate from lysogenic starter cultures, although the majority of industrial host strains used in this study contain prophages of P335-type in their chromosomes. The observed lysogenicity of the strains is in agreement with the results from previous studies which showed that lactococcal starter culture strains are commonly found to carry prophages (Huggins \& Sandine, 1977; Gasson, 1980; Terzaghi \& Sandine, 1981; Reyrolle et al., 1982). The lack of P335-type phages in the analyzed whey samples is also consistent with the idea that lytic phages from this type appeared in the dairy environment only recently (Moineau et al., 1993). Nevertheless, even if an induction of prophages of P335-type occurred, they were undetectable in the wheys under the conditions of the multiplex PCR assay. This suggests that P335-type phages constituted a small minority, if at all, of phage particles present in the examined wheys and could not have been the cause of biotechnological problems.

In our study, no correlation between plaque morphology and phage DNA restriction pattern was observed. Phages from different restriction and genetic groups were noted to be able to propagate in the same host, which implies that there is no relation between DNA homology and host specificity.

Lactococcal phages identified in this work were found to belong to either the c2 or 936 types of lytic phages. Yet, the frequencies at which the two phage types were isolated differed - 936-type phages appeared more commonly than c2-type phages. This observation is consistent with reports from other European countries as well as from New Zealand, United States or Canada, where the lytic lactococcal 936-type phages were found to dominate (Jarvis, 1984; Prevots et al., 1990; Casey et al., 1993; Moineau et al., 1996; Bissonnette et al., 2000; Miklic \& Rogelj, 2003). Notably, a different situation was reported in countries localized nearby Poland. In Germany, $60 \%$ of the analyzed phages were classified as c2-type, while a similar study in Denmark established the prevalence of phages from the P335 type (Lembke et al., 1980; Josephsen et al., 1999). Earlier publications show that the type of the isolated phages is correlated with bacterial strains used in starter culture mixes (Jarvis, 1989; Daly et al., 1996). It has been noted that starter cultures containing defined strains, mainly L. lactis subsp. cremoris, favor isometric-headed phage propagation, including the 936 type, while mix starter cultures contain an excess of L. lactis subsp. lactis and L. lactis subsp. lactis var. diacetylactis strains, which are hosts for c2-type prolate-headed phages. Based on our observations, a preference for defined starter cultures in dairy plants in Poland can be suggested.
Most cultures monitored were lysed after $2 \mathrm{~h}$ following infection, indicating a fast phage lysis rate. The majority of the studied phages exhibited a narrow host spectrum. The c2-type phages isolated in this study displayed a wider host range than the 936-type phages. This observation is consistent with earlier reports stating that c2-type phages are less specific to bacterial strains and demonstrate a large host spectrum (Heap \& Jarvis, 1980; Lodics \& Steenson, 1990; Moineau et al., 1992; 1996; Miklic \& Rogelj, 2003). Yet, notably, the two most prevalent phages - bIBB5g $_{1}$ and bIBBEg $_{1}$ - which each infected only one L. lactis subsp. lactis var. diacetylactis starter strain, were found to belong to the 936 type. The common occurrence of these two phages in various dairy plants is most likely connected with the frequent exploitation of the sensitive bacterial strains throughout the whole country and specialization of the predominant phages towards these two strains. Strains employed in this study have been selected among potentially phage-resistant bacteria used as industrial starters, which supports the fact that almost $94 \%$ of the phages were specific for only one or two bacterial strains and four strains were resistant to all phages tested. Yet, the fast lysis rate and narrow host range reflect phage specialization to the starter strains exploited in the dairy environment. On the other hand, certain strains are sensitive to both c2- and 936-type phages, which suggests that phages of different types have independently developed an adaptation of infecting the same strain.

Analysis of the actual state of phages predominant in the dairy industry in Poland shows that lactococcal phages prevail and are still a common cause of fermentation perturbations. The incidence of phage infections in milk plants rises with the worldwide development of this industrial branch, a direct result of the increase of the amount of processed milk. Our collection of industrial starter cultures and lactococcal phages isolated from industrial whey samples supplies a valuable reference on phage-resistant starter cultures and phages most commonly occurring in dairies. Elimination or reduction of phage infection incidences depend highly on the multiple strain starters used. Successful employment of starter bacteria is associated with a number of factors; primarily, with selecting strains with relatively low phage-sensitivity that will be able to endure the attack of phages. Therefore, a wider knowledge of phages present in dairy plants as well as of their biology seems indispensable.

\section{Acknowledgements}

This work was supported by The State Committee for Scientific Research (KBN) grant No. 3 P06T 05123 and partially financed by the Ministry of Science and Higher Education, project "Bacteri- 
ophage Biology and Biotechnology Network" (decision No. 1/E-35/S/2006-2).

\section{REFERENCES}

Bissonnette F, Labrie S, Deveau H, Lamoureux M, Moineau S (2000) Characterization of mesophilic mixed starter cultures used for the manufacture of aged cheddar cheese. J Dairy Sci 83: 620-627.

Braun V, Teuber M, Geis A, Hertwig SJR, Neve H (1989) Taxonomic differentiation of bacteriophages of Lactococcus lactis by electron microscopy, DNA-DNA hybridization and protein profiles. J Gen Microbiol 135: 2551-2560.

Casey CN, Morgan E, Daly C, Fitzgerald GF (1993) Characterization and classification of virulent lactococcal bacteriophages isolated from a cheddar cheese plant. $J$ Appl Bacteriol 74: 268-275.

Chopin A, Chopin M-C, Moillo-Batt A, Langella P (1984) Two plasmid-determined restriction and modification systems in Streptococcus lactis. Plasmid 11: 260-263.

Coffey A, Ross RP (2002) Bacteriophage-resistance systems in dairy starter strains: molecular analysis to application. Antonie van Leeuwenhoek 82: 303-321.

Daly C, Fitzgerald GF, Davis R (1996) Biotechnology of lactic acid bacteria with special reference to bacteriophage resistance. Antonie van Leeuwenhoek 70: 99-110.

Gasson MJ (1983) Plasmid complements of Streptococcus lactis NCDO 712 and other lactic streptococci after protoplast-induced curing. J Bacteriol 154: 1-9.

Gasson MJ, Davies FL (1980) Prophage-cured derivatives of Streptococcus lactis and Streptococcus cremoris. Appl Environ Microbiol 40: 964-966.

Heap HA, Jarvis AW (1980) A comparison of prolate- and isometric-headed lactic streptococcal bacteriophages. New Zealand J Dairy Sci Technol 15: 75-81.

Hejnowicz MS, Bardowski J (2005) Bacteriophage infections of mesophilic bacteria in dairy industry. Polish Dairy J 7: 2-7 (in Polish).

Huggins AR, Sandine WE (1977) Incidence and properties of temperate bacteriophages induced from lactic streptococci. Appl Environ Microbiol 33: 184-191.

Jarvis AW (1977) The serological differentiation of lactic streptococcal bacteriophages. New Zealand J Dairy Sci Technol 12: 176-181.

Jarvis AW (1984) Differentiation of lactic streptococcal phages into phage species by DNA-DNA homology. Appl Environ Microbiol 47: 343-349.

Jarvis AW (1989) Bacteriophages of lactic acid bacteria. J Dairy Sci 72: 3406-3428.

Jarvis AW, Fitzgerald GF, Mata M, Mercenier A, Neve H, Powell IA, Ronda C, Saxelin M, Teuber M (1991) Species and type phages of lactococcal bacteriophages. Intervirology 32: 2-9.

Josephsen J, Petersen A, Neve H, Nielsen EW (1999) Development of lytic Lactococcus lactis bacteriophages in a Cheddar cheese plant. Int J Food Microbiol 50: 163-171.

Labrie S, Moineau S (2000) Multiplex PCR for detection and identification of lactococcal bacteriophages. Appl Environ Microbiol 66: 987-994.

Lawrence RC (1978) Action of bacteriophage on lactic acid bacteria: consequences and protection. New Zealand J Dairy Sci Technol 13: 129-136.

Lembke J, Krisch U, Lompe A, Teuber M (1980) Isolation and ultrastructure of bacteriophages of group $\mathrm{N}$ (lactic) streptococci. Zentbl Bakteriol Abt Orig C 1: 79-91.
Lodics TA, Steenson LR (1990) Characterization of bacteriophages and bacteria indigenous to a mixed-strain cheese starter. J Dairy Sci 73: 2685-2696.

Madera C, Monjardin C, Suarez JE (2004) Milk contamination and resistance to processing conditions determined the fate of Lactococcus lactis bacteriophages in dairies. Appl Environ Microbiol 70: 7365-7371.

McIntyre K, Heap HA, Davey GP, Limsowtin GKY (1991) The distribution of lactococcal bacteriophage in the environment of cheese manufacturing plant. Int Dairy J 1: 183-197.

Miklic A, Rogelj I (2003) Characterization of lactococcal bacteriophages isolated from Slovenian dairies. Int $J$ Food Sci Technol 38: 305-311.

Moineau S, Fortier J, Ackermann H-W, Pandian S (1992) Characterization of lactococcal bacteriophages from Quebec cheese plants. Can J Microbiol 38: 875-882.

Moineau S, Pandian S, Klaenhammer TR (1993) R/M systems and restriction endonucleases are more effective on lactococcal bacteriophages that have emerged recently in the industry. Appl Environ Microbiol 59: 197202.

Moineau S, Borkaev M, Holler BJ, Walker SA, Kondo JK, Vedamuthu ER, Vandenbergh PA (1996) Isolation and characterization of lactococcal bacteriophages from cultured buttermilk plants in United States. J Dairy Sci 79: 2104-2111.

Pillidge CJ, Jarvis AW (1988) DNA restriction maps and classification of the lactococcal bacteriophages c2 and sk1. New Zealand J Dairy Sci Technol 23: 411-416.

Powell IB, Arnold PM, Hillier AJ, Davidson BE (1989) Molecular comparison of prolate- and isometric-headed bacteriophages of lactococci. Can J Microbiol 35: 860866.

Prevots F, Mata M, Ritzenthaler P (1990) Taxonomic differentiation of 101 lactococcal bacteriophages and characterization of bacteriophages with unusually large genomes. Appl Environ Microbiol 56: 2180-2185.

Relano P, Mata M, Bonneau M, Ritzenthaler P (1987) Molecular characterization and comparison of 38 virulent and temperate bacteriophages of Streptococcus lactis. J Gen Microbiol 133: 3053-3063.

Reyrolle J, Chopin M-C, Letellier F, Novel G (1982) Lysogenic strains of lactic acid streptococci and lytic spectra of their temperate bacteriophages. Appl Environ Microbiol 43: 349-356.

Sambrook J, Fritsch EF, Maniatis T (1989) Molecular cloning. In A laboratory manual. Cold Spring Harbor Laboratories, Cold Spring Harbor, N.Y.

Sanlibaba P, Akcelik M (2005) Classification of virulent lactococcal bacteriophages based on protein composition and restriction endonuclease analysis. Turk J Vet Anim Sci 29: 865-871.

Schouler C (1996) Genomic organization of lactic acid bacteria phages. Lait 76: 81-89.

Sing WD, Klaenhammer TR (1993) A strategy for rotation of different bacteriophage defenses in a lactococcal single-strain starter culture system. Appl Environ Microbiol 59: 365-372.

Terzaghi BE, Sandine WE (1975) Improved medium for lactic streptococci and their bacteriophages. Appl Microbiol 29: 807-813.

Terzaghi BE, Sandine WE (1981) Bacteriophage production following exposure of lactic streptococci to ultraviolet radiation. J Gen Microbiol 122: 305-311. 